\title{
Epidemiologic Findings from Case Investigations and Contact Tracing for First 200 Cases of Coronavirus Disease, Santa Clara County, California, USA
}

Nancy Ortiz, Elsa Villarino, James T. Lee, Kristina L. Bajema, Jessica N. Ricaldi, Shanon Smith, Wen Lin, Margaret Cortese, Albert E. Barskey, Juliana F. Da Silva, Brandon J. Bonin, Sarah L. Rudman, George S. Han, Marc Fischer, Shua J. Chai, Sara H. Cody, for the Santa Clara County COVID-19 Case Investigation Team

In January 2020, Santa Clara County, California, USA, began identifying laboratory-confirmed coronavirus disease among residents. County staff conducted case and contact investigations focused on households and collected detailed case demographic, occupation, exposure, and outcome information. We describe the first 200 test-positive cases during January 31-March 20, 2020, to inform future case and contact investigations. Probable infection sources included community transmission (104 cases), known close contact with a confirmed case-patient (66 cases), and travel (30 cases). Disease patterns across race and ethnicity, occupational, and household factors suggested multiple infection risk factors. Disproportionately high percentages of case-patients from racial and ethnic subgroups worked outside the home (Hispanic [86\%] and Filipino [100\%]); household transmission was more common among persons from Vietnam (53\%). Even with the few initial cases, detailed case and contact investigations of household contacts capturing occupational and disaggregated race and ethnicity data helped identify at-risk groups and focused solutions for disease control.

$O_{\mathrm{p} a}$ January 31, 2020, the Santa Clara County Department of Public Health (SCCDPH) in San Jose, California, USA, identified its first case of coronavirus disease (COVID-19) in a resident who had recently returned from Wuhan, China (1). On February

Author affiliations: Centers for Disease Control and Prevention, Atlanta, Georgia, USA (N. Ortiz, J.T. Lee, K.L. Bajema,

J.N. Ricaldi, M. Cortese, A.E. Barskey, J.F. Da Silva, M. Fischer,

S.J. Chai); County of Santa Clara Public Health Department,

San Jose, California, USA (E. Villarino, S. Smith, W. Lin,

B.J. Bonin, S.L. Rudman, G.S. Han, S.H. Cody)

DOI: https://doi.org/10.3201/eid2705.204876
28 , the county reported its first case of COVID-19 associated with probable community transmission, 48 hours after the first presumed community-acquired case in the United States was identified 91 miles north in Solano County (2). Staff of the SCCDPH, the California Department of Public Health, and the Centers for Disease Control and Prevention (CDC) began conducting detailed interviews with each case-patient or their surrogate to identify, quarantine, and monitor close contacts, and isolate and test those who were symptomatic. Santa Clara initiated a series of community mitigation strategies to slow the spread of the virus that causes COVID-19, severe acute respiratory syndrome coronavirus 2 (SARS-CoV-2), including canceling large gatherings $(3,4)$. On March 16, Santa Clara and 5 adjacent San Francisco Bay Area counties became the first US region to implement shelter-inplace orders requiring all residents to limit activity outside of their home and to order nonessential businesses and operations to close (5). SCCPHD collected detailed information on demographic characteristics to help identify communities at risk and those disproportionately affected by COVID-19. Since the initial identification of cases, surges in COVID-19 incidence have often constrained public health and community capacity to respond, including overwhelming case and contact investigation efforts. We describe the epidemiology of the first 200 COVID-19 cases reported to SCCPHD to identify key transmission factors that could already be identified early in the COVID-19 pandemic through detailed case investigation and

${ }^{1}$ Members of the Santa Clara County COVID-19 Case

Investigation Team are listed at the end of this article. 
contact tracing focused on households and to demonstrate the utility of focusing these efforts throughout the pandemic response.

\section{Methods}

\section{Case Identification and Testing}

We defined a confirmed COVID-19 case as an illness in a resident of Santa Clara County with SARS-CoV-2 detected by reverse transcription PCR (RT-PCR) on a nasopharyngeal or oropharyngeal swab specimen by a public health, hospital, or reference clinical microbiology laboratory or CDC. Testing was recommended in line with the following evolving CDC Person Under Investigation case definition: clinical findings of lower respiratory illness and travel to Wuhan, China (later expanded to all of China) or an epidemiologic link to a laboratory-confirmed COVID-19 case $(6,7)$; hospitalization for severe respiratory disease and no alternative diagnosis (8); and clinically compatible illness regardless of travel or known contact with a confirmed case-patient. Included COVID-19 case-patients comprised those reported to SCCDPH and those identified by a community-based sentinel surveillance project for COVID-19 conducted during March 5-14, 2020, among clinic patients with respiratory illness who tested negative for influenza virus (9). This activity was reviewed by CDC and was conducted consistent with applicable federal law and CDC policy.

\section{Case Investigation and Contact Tracing}

SCCDPH, California Department of Public Health, and CDC staff identified cases reported to California's electronic reportable disease system. Staff interviewed COVID-19 cases or their surrogates for information on case age, sex, race, ethnicity, address, occupation, travel history, known contact with another confirmed case-patient, symptom onset (earliest of any symptoms listed on CDC's standardized case report form) (10), and hospitalization. Investigators collected detailed race and ethnicity data, including racial subgroup among case-patients reporting Asian ancestry.

Case-patients with no recent travel and no known close contact with another confirmed casepatient in the 2 weeks before symptom onset were classified as probable community transmission. Known close contact was defined as living with, caring for, working with, transporting, or prolonged exposure (close contact $<6$ feet for $\geq 30$ minutes) to a person with confirmed COVID-19. Case-patients with any travel outside of Santa Clara County in the
2 weeks before their symptom onset were considered travel-associated cases.

SCCPHD's contact tracing involved identifying persons with close contact with the case-patient 2 weeks after the case-patient's symptom onset and notifying contacts of their exposure. Owing to the rapid rise in case counts and limited personnel capacity, the team focused on following up with household contacts. In-hospital outcomes were collected from review of medical records and case-patient interviews. Deaths through May 20, 2020 (60 days after the 200th case was reported), were defined as COVID-19associated if the cause or other contributing cause on the death certificate was listed as COVID-19.

\section{Data Analysis}

We collected data using standard forms and openended case-patient interviews and entered results into Excel 365 (Microsoft, https://www.microsoft. com) and California's electronic reportable disease system. Categorical variables were described as counts and percentages, and continuous variables were described using median and range. We estimated associations between illness severity measures (hospitalization defined as admission for $\geq 1$ night in an inpatient acute-care facility [including intensivecare unit (ICU) stay and mechanical intubation with ventilation]; ICU stay [including mechanical ventilation]; mechanical ventilation; and death) as the dependent variables, and age and sex as independent variables with odds ratios (ORs) and 95\% CIs using bivariate logistic regression. Because of the limited number of cases, to avoid invalid results or unstable models, measurements were not adjusted. We analyzed data using Stata 14 (StataCorp, https:/ / www. stata.com) and Epi Info version 7 (Epi Info, https:/ / www.cdc.gov/epiinfo) and generated maps using Excel 365 (Microsoft, https:/ / www.microsoft.com).

\section{Results}

\section{Case Description}

Of the 200 cases with laboratory confirmation of SARCoV-2 positivity during January 31-March 20, 2020, a total of 191 (96\%) were identified through routine surveillance and contact tracing and $9(4 \%)$ were identified through clinic-based sentinel surveillance. Onset of illness ranged from January 24 through March 18; these case-patients were exposed before shelter-inplace orders were invoked (Figure 1). Among the first cases identified during January 31-February 2, travel accounted for the largest reported source of exposure. Over subsequent weeks, case-patients reported 


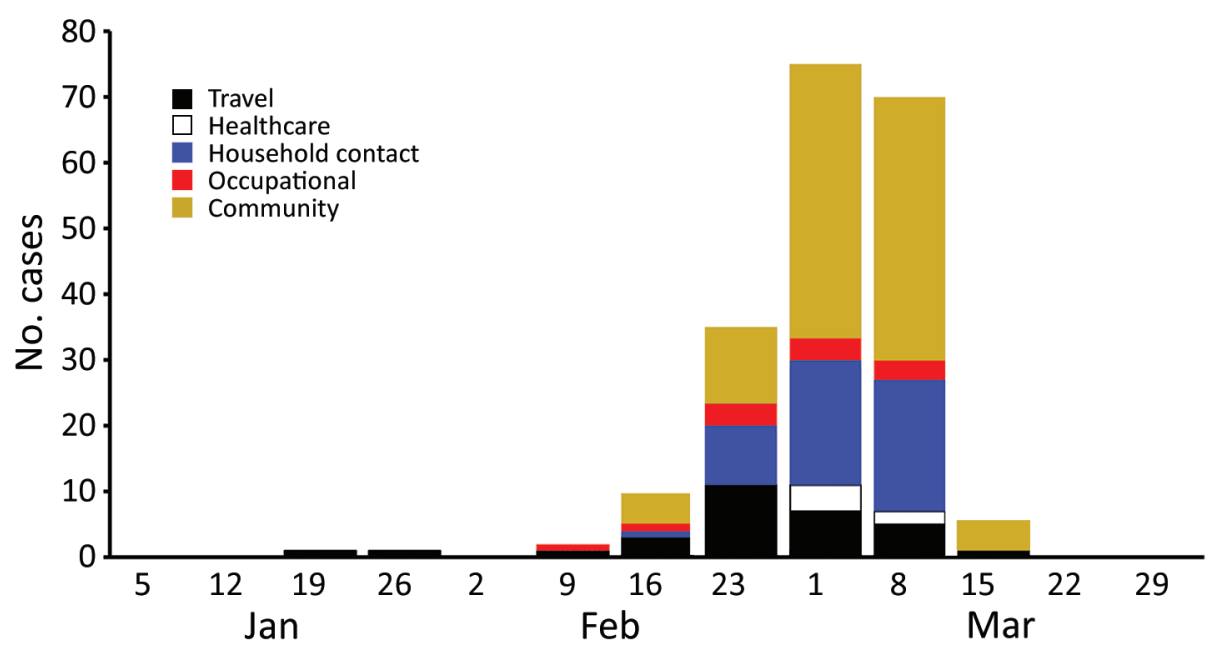

Figure 1. Week of symptom onset, for first 200 confirmed coronavirus disease cases, by exposure source, Santa Clara County, California, USA, January 31-March 20, 2020.

unknown and household exposure at higher frequencies than other exposures. The percentage of casepatients who were hospitalized decreased over time as testing availability increased and focus of testing broadened to include additional populations, including symptomatic contacts.

Among the 200 case-patients, 112 (56\%) were male, and the median age was 50 years (range 6 months-94 years); only $10(5 \%)$ case-patients were $<20$ years of age, whereas $71(36 \%)$ were $\geq 60$ years of age (Table, https:/ / wwwncdc.gov/EID/article/27/5/20-4876-T1.htm). The racial and ethnic distribution of case-patients was similar to that of the county population overall: 70 (35\%) reported as Asian, 52 (26\%) Hispanic, 52 (26\%) White non-Hispanic, 4 (2\%) Black non-Hispanic, and 3 (1\%) Pacific Islander; race or ethnicity was unknown for 19 (9\%) case-patients. Although Asian-identifying persons comprised a similar proportion of case-patients as that of Santa Clara County, a higher proportion of case-patients identified as Filipino (10\% vs. 5\%), a similar proportion as Vietnamese ( $7 \%$ vs. $7 \%)$, and a lower proportion as Indian (4\% vs. $9 \%)$ or Chinese $(4 \%$ vs. $10 \%)$ than among the general population of Santa Clara County $(11,12)$. Of the 200 case-patients, 89 (44\%) were hospitalized (Table); 45 (23\%) were on a general ward, $18(9 \%)$ were admitted to an ICU without requiring mechanical ventilation, and 26 (13\%) required mechanical ventilation in an ICU. The proportion of case-patients hospitalized, admitted to the ICU, requiring mechanical ventilation, and who died each increased with increasing age (Figure 2). Compared with case-patients $<60$ years of age, case-patients $\geq 60$ years of age had higher odds of hospitalization (OR 4.4 [95\% CI 2.4-8.3]), ICU stay (OR 10.9 [95\% CI 4.9-24.2]), mechanical ventilation (OR 6.3 [95\% CI 2.5-16.0]), and death (OR 9.0 [95\% CI 2.9-28.4]). No statistically significant association was observed between clinical outcomes and sex.

Among the 200 case-patients, $20(10 \%)$ had a matching death certificate. The median age of deceased case-patients was 70.5 years (range 42-87 years), and 15 (75\%) were male. Among the 20 casepatients who died, $9(45 \%)$ were Asian, $5(25 \%)$ were White non-Hispanic, 2 (10\%) were Hispanic, and 4 $(20 \%)$ had unknown race or ethnicity. Five $(25 \%)$ of the 20 deaths occurred among persons of Filipino ethnicity; these case-patients did not have a known close contact to one another.

Case-patient residences were distributed among $47(79 \%)$ of the 59 ZIP codes in the county; $18(30 \%)$ ZIP codes had $1-2$ cases, 13 (22\%) had 3-4 cases, and $16(8 \%)$ had $\geq 5$ cases (Figure 3, panel A). Case-patient residences clustered in the northeastern part of the county, where 2 adjacent ZIP codes accounted for 36 $(18 \%)$ of the 200 case-patients; in the ZIP code with the most cases, 9 were associated with a single household. COVID-19 incidence rates by ZIP code ranged from $0-113$ cases $/ 100,000$ persons; rates were generally highest in eastern ZIP codes in the county (Figure 3, panel B).

\section{Exposure Type and Setting}

Of the 200 case-patients, 66 (33\%) had known close contact with another confirmed case-patient, 30 (15\%) were considered travel-associated cases (Table), and $104(52 \%)$ were attributable to probable community transmission. Among the 66 case-patients with known close contact with another confirmed case-patient, 49 (74\%) were exposed to a household member, and 17 (26\%) had occupational exposures. Most households with evidence of transmission (13/15 [86\%]) had 2-3 confirmed case-patients identified. However, 2 


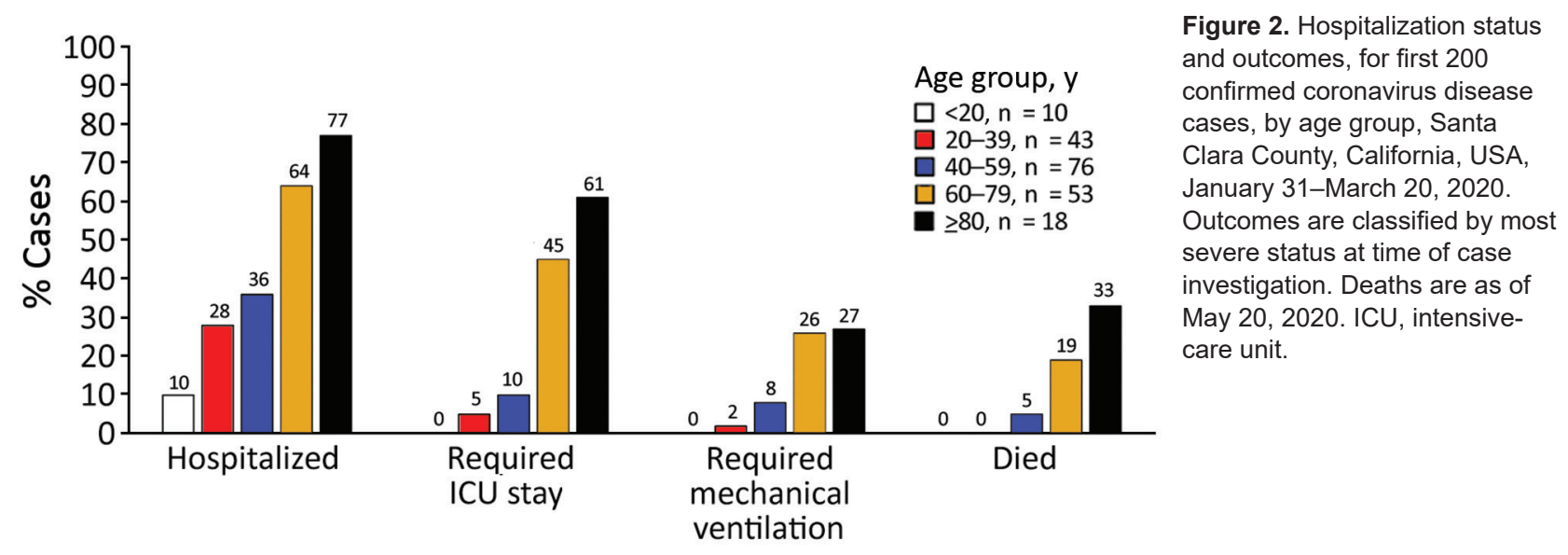

multigenerational households each had 9 and 4 casepatients; the cluster of 4 case-patients was only identified as a result of contact tracing.

Of the 200 case-patients, 159 (79\%) were adults with reported occupation. Of these, 111 (69\%) were actively employed (not retired and reported employment), and of these, $82(73 \%)$ reported jobs requiring work outside the home, which included healthcare workers, firefighters, food service workers, retail employees, construction workers, housekeepers, and other workers. Among these 82 case-patients reporting jobs requiring work outside the home, $46 \%$ of exposures were attributable to probable community transmission, followed by $22 \%$ household and $21 \%$ occupational exposures.

Type and location of exposure, as well as having an occupation that requires work outside the home, varied by race and ethnicity. Among 49 cases in Hispanic adults, occupation was known for $44(89 \%)$; of the 38 actively employed, $89 \%$ held occupations that required them to work outside of the home. Occupation was known for 16 of 20 Filipino case-patients; for the 9 case-patients who were actively employed, all had jobs outside the home. Occupational exposure to a confirmed case-patient, including in a healthcare setting, accounted for 5 (25\%) of 20 cases in Filipino persons, compared with $12(7 \%)$ of all other cases with reported race and ethnicity. Household transmission accounted for exposures in $53 \%$ of Vietnamese casepatients and $32 \%$ of Hispanic case-patients, compared with $23 \%$ of all other case-patients with known race/ ethnicity. Among case-patients of Indian and Chinese ethnicity, $>50 \%$ had travel-related exposures.

Among the 17 case-patients with an occupational exposure to a confirmed case-patient, 11 (64\%) exposures occurred in a nonhealthcare setting. Of these 11, all were employed as essential workers in occupations or settings in which they had frequent contact with many persons in the community. Occupational clusters and groupings included 6 airport employees, 4 employees at a supermarket, 3 childcare workers who shared a classroom and bathroom, and 2 firefighters who worked at the same station. At least 3 additional cases were identified among other firefighters who worked at the same station or attended a common function but were not Santa Clara County residents.

Of the 200 case-patients, $16(8 \%)$ were healthcare workers with jobs that provided direct patient care or were first responders with direct patient exposure, of whom $8(50 \%)$ were nurses. Only 6 transported, cared for, or had other known close contact with a confirmed case-patient in a healthcare setting. Of the other 10 cases in healthcare workers, 1 case-patient had travel-related expo- sure, 3 had known close contact with a case-patient in their household, and 6 did not have exposure to a known COVID-19 casepatient and were categorized as attributable to probable community transmission.

\section{Discussion}

Detailed case investigations and household contact tracing of the first 200 case-patients of COVID-19 in Santa Clara County were able to help elucidate factors associated with being a COVID-19 case-patient and identify populations at risk for infection early in the response, including possible racial and ethnic disparities, elevated risks within households, and high-risk occupational groups. Many of these factors and populations at risk were subsequently confirmed by studies later in the pandemic $(13,14)$. Case investigations identified possible sources of transmission in $96(48 \%)$ of cases, and for those case-patients with known exposure, household transmission was the most commonly reported source, especially in Vietnamese and Hispanic communities. Work outside the 
home was commonly reported by Hispanic case-patients. Case-patients $\geq 60$ years of age had significantly higher odds of being hospitalized, being admitted to the ICU, requiring mechanical ventilation, and dying; these findings are consistent with reports from China, Italy, and other parts of the United States (15-17).

Because SCCPHD conducted contact tracing and monitoring specifically among household contacts of case-patients, the finding that approximately one quarter of the first 200 case-patients were household contacts of a confirmed case-patient is not surprising. However, SCCPHD's prioritization of contact tracing and monitoring contacts within households early in the pandemic was high-yield, and findings were consistent with disease transmission factors for COVID-19 reported in subsequent studies $(18,19)$. Investigations identified not only that older persons had increased odds of poor outcomes from COVID-19 but also that casepatients with multiple factors potentially increased risk. For example, several large clusters were identified within families that consisted of members of multiple generations, and several individuals $>80$ years of age might have been exposed. In 2 of these clusters, the index case-patient was a nonelderly household member who presumably transmitted SARS-CoV-2 to elderly household members. Anecdotally, several of these households also reported crowding and inability to self-isolate from other members within the home (Santa Clara COVID-19 Case Investigation Team, pers. comm., group discussion during case review, March 2020). Households have been identified as a high-risk setting for SARS-CoV-2 transmission (20-22), and household crowding is a risk factor for COVID-19 (23). In the ZIP code with the highest case rate in northeast Santa Clara, $14 \%$ of households are overcrowded $(>1.0$ persons/room), as measured by the American Community Survey, compared with the median of $6 \%$ of households in Santa Clara County as a whole (24). Although information on an individual case-patient's household density was not collected as part of case and contact investigations, 4 (33\%) of 12 ZIP codes where household transmission was identified reported $>10 \%$ frequency of overcrowded households, compared with $7(20 \%)$ of 35 ZIP codes where cases were identified but no household transmission was noted. Household density might be associated with other factors, such as high-risk occupations of household members $(25,26)$, to increased risk for COVID-19 within households. Case investigators collecting information regarding household density during interviews can help not only to elucidate transmission risk in a particular household, but also link persons at high risk for poor outcomes to resources to prevent household transmission. One example of a solution to prevent household transmission is The NYC Test and Trace Corps, a collaborative public health program led by NYC Health + Hospitals in collaboration with the New York City Department of Public Health and Mental Hygiene, which offers hotel stays for persons who have COVID-19, exhibit COVID-19 symptoms, or are contacts of a known COVID-19 case-patient and who need to isolate or quarantine from household members (27).
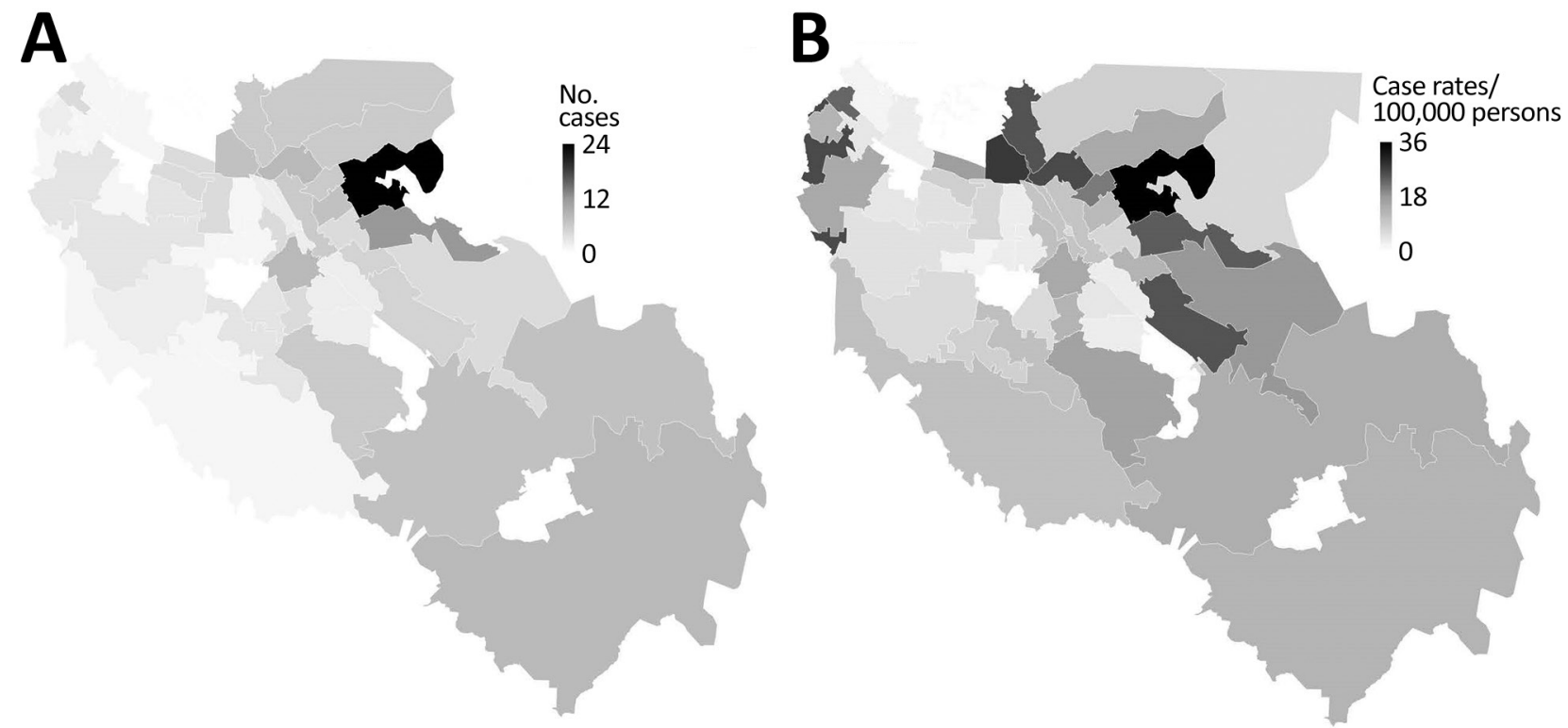

Figure 3. Geographic location of first 200 confirmed coronavirus disease cases, by case-patient's ZIP code area of residence (for those areas with >2,000 residents), Santa Clara County, California, USA, January 31-March 20, 2020. A) No. cases; B) case rate (cases/100,000 population). 
Working outside the home, especially with public-facing duties (e.g., airport workers), was especially common in this early cohort; $>40 \%$ of casepatients reported an occupation that did not allow them to work from home. A large frequency of casepatients who performed work outside the home did not report a known exposure or travel, suggesting that difficult-to-trace exposures, such as exposure to someone the case-patient did not know or did not know was infected, probably occurred (28). Moreover, occupational exposures were probably more common than we reported, because case-patients who did not have known exposure to a person with confirmed COVID-19 and had not traveled were classified as having community exposure. Identifying the source of exposure for case-patients with occupations that interact with the public might prove to be very labor-intensive or impossible, given the number of potential contacts involved. However, case and contact investigations, at a minimum, should include notifying co-workers and alerting employers to a positive case in a workplace (29) and collecting occupation data to help identify occupational subgroups at risk.

Occupational exposures probably differed by racial and ethnic groups among the first 200 casepatients in Santa Clara County. Among employed Filipino case-patients, all held jobs that required work outside the home. Although few Hispanic case-patients reported an occupational exposure with a confirmed COVID-19 case-patient, a greater percentage of Hispanic case-patients $(89 \%)$ had occupations that required them to work outside the home than did White non-Hispanic case-patients $(56 \%)$. Many of the Hispanic case-patients in Santa Clara County communicated that they could not afford the lost wages that would result from staying home from work (Santa Clara COVID-19 Case Investigation Team, pers. comm., group discussion during case review, March 2020). Hispanic persons nationwide have reported higher frequencies of job loss and wage reduction because of the COVID-19 pandemic compared with persons from other racial and ethnic minority groups, and less than one third of Hispanic persons surveyed reported that they could weather a financial emergency (30). These financial and occupational factors together might be critical drivers for transmission within the Hispanic population in Santa Clara County and perhaps statewide, where Hispanic persons have accounted for a disproportionately high number of cases (31). A disproportionately high percentage of COVID-19 cases and deaths occurred in Filipino persons; cases among Filipino persons associated with occupational exposures involved providing direct patient care to known COVID-19 patients or contact with a person with confirmed COVID-19 in publicfacing service jobs.

Household exposures also differed by racial and ethnic groups. Vietnamese and Hispanic casepatients more frequently reported exposure to a person with confirmed COVID-19 in their household compared with case-patients from other race and ethnicity groups. Anecdotally, among Vietnamese and Hispanic case-patients, $\geq 3$ reported living in multigenerational households with high densities of persons and an inability to self-isolate within the home, posing a serious risk to older adults residing in these households. Household case clusters occurred in eastern ZIP codes that had high percentages of Hispanic persons (58\% of the population in the ZIP code with the most cases and highest rates) and Vietnamese persons (22\%), compared with $26 \%$ of Hispanic and 7\% of Vietnamese persons in the county as a whole (32-37). Together, these findings suggest that household crowding might be an especially important driver of household transmission in traditionally underserved communities.

Few of the first 200 COVID-19 cases in Santa Clara County occurred in healthcare workers or persons in institutional or congregate living settings. Although more than one third of infected healthcare workers reported an occupational exposure and a quarter traveled or had a nonoccupational close-contact exposure, none of these exposures was identified for $40 \%$ of them. Evidence to date does not support substantial occupational transmission of SARS-CoV-2 to healthcare workers (38). Community transmission could have been an important source of exposure for healthcare workers, given the widespread community transmission occurring simultaneously in Santa Clara County.

One limitation of this analysis is, as with most reports on COVID-19, case identification was largely dictated by testing practices. At the start of the outbreak, the number of persons eligible for testing according to CDC criteria and testing capacity were limited, biasing these initial findings to case-patients with higher disease and mortality rates and to persons with recent travel or known contact with a confirmed case-patient. Had testing been more widely available and criteria included milder symptoms or risk for exposure regardless of symptoms, broader or earlier detection of community transmission might have occurred. This 
investigation occurred when information was limited for this new and emerging disease. The definition of prolonged COVID-19 exposure and guidance for case and contact investigations has been updated since this investigation concluded (39). Although we observed differences in sources of exposure by race and ethnicity, data on race were missing for $19(9 \%)$ cases and racial subgroup for $16(23 \%)$ of 70 cases among Asian persons; therefore, these data should be interpreted with caution. Our data reflect the epidemiology of COVID-19 in Santa Clara early in the pandemic among those with clinical manifestations that were eligible for testing and probably are not reflective of the current epidemiology (40).

Even with results from only the first 200 case-patients, detailed case investigation and contact tracing focused on households revealed patterns of at-risk populations, including older age adults, racial and ethnic subgroups, occupational categories, and potentially crowded households. Detailed case reviews, including disaggregation of race and ethnicity data, helped identify local factors of transmission and disparities important for public health intervention. Importantly, occupational exposures continue to be a source of infection (41), and understanding transmission risk within specific occupational settings, especially among professions that require persons to work outside their homes, is important to ensure safe workplaces and reopening of economies as the pandemic continues to evolve. As mitigation measures to suppress community transmission evolve throughout the pandemic response, novel preventive measures (e.g., temporary housing) might continue to be necessary to protect disproportionately affected subpopulations and older adults.

\section{Members of the Santa Clara County COVID-19 Case Investigation Team: Nora Chea, Calin Chiribau, Lindsey Duca, Joseph Hicks, Jimee Hwang, Jessica Leung, Joel London, Huong Pham, Matthew Stuckey, Diya Surie, Kathleen Thurman, and Douglas Trout.}

\section{Acknowledgments}

We thank the Case Investigation Team for their support in the field.

\section{About the Author}

Dr. Ortiz is an Epidemic Intelligence Service Officer in the Division of Scientific Education And Professional Development, Center For Surveillance, Epidemiology, and Laboratory Services, Centers for Disease Control and Prevention. Her research interests include infectious diseases, emerging infections, and applied epidemiology.

\section{References}

1. Santa Clara County Public Health Department. Letter from the Health Officer. February 3, 2020 [cited 2021 Jan 28]. https://www.sccgov.org/sites/covid19/Pages/ health-officer-letter-2-3-2020.aspx

2. Santa Clara County Public Health Department. County of Santa Clara Public Health Department reports third case of COVID-19. February 28, 2020 [cited 2021 Jan 28]. https://www.sccgov.org/sites/phd/news/Pages/ third-novel-coronavirus-case-02-2020.aspx

3. Santa Clara County Public Health Department. County of Santa Clara issues order to cancel mass gatherings due to increasing rates of COVID-19. March 9, 2020 [cited 2021 Jan 28]. https://www.sccgov.org/sites/phd/news/Pages/ order-health-officer-03092020.aspx

4. Santa Clara County Public Health Department. Due to increasing rates of COVID-19, County Public Health issues new order cancelling gatherings of more than 100 people and restricting gatherings of more than 35 people. March 13, 2020 [cited 2021 Jan 28]. https:/ / www.sccgov.org/sites/phd/ news/Pages/ press-release-03-13-20.aspx.

5. Santa Clara County Public Health Department. Seven bay area jurisdictions order residents to stay home. March 16, 2020 [cited 2021 Jan 28]. https:/ / www.sccgov.org/sites/ phd/news/Pages/ press-release-03-16-20.aspx

6. Centers for Disease Control and Prevention. Health alert network: update and interim guidance on outbreak of 2019 novel coronavirus (2019-nCOV) in Wuhan, China. 2020 [cited 2021 Jan 28]. https:/ / emergency.cdc.gov/han/ han00427.asp

7. Centers for Disease Control and Prevention. Health alert network: update and interim guidance on outbreak of 2019 novel coronavirus (2019-nCOV) in Wuhan, China. 2020 [cited 2021 Jan 28]. https:/ / emergency.cdc.gov/han/han00426.asp

8. Centers for Disease Control and Prevention. Update and interim guidance on outbreak of coronavirus disease 2019 (COVID-19). February 28, 2020 [cited 2021 Jan 28]. https:/ / emergency.cdc.gov/han/2020/han00428.asp

9. Zwald ML, Lin W, Sondermeyer Cooksey GL, Weiss C, Suarez A, Fischer M, et al. Rapid sentinel surveillance for COVID-19-Santa Clara County, California, March 2020. MMWR Morb Mortal Wkly Rep. 2020;69:419-21. https://doi.org/10.15585/mmwr.mm6914e3

10. Centers for Disease Control and Prevention. Human infection with 2019 novel coronavirus case report form [cited 2021 Jan 29]. https:/ / www.cdc.gov/coronavirus/ 2019-ncov/downloads/pui-form.pdf

11. US Census Bureau. United States Census. Quick facts: Santa Clara County, California. July 1, 2019 [cited 2021 Jan 28]. https:/ / www.census.gov/quickfacts/ santaclaracountycalifornia

12. US Census Bureau. 2018 American Community Survey 5-year estimates, demographic and housing estimates, Table DP05 [cited 2021 Jan 28]. https:/ / data.census.gov/cedsci/ table?g=0400000US06_0500000US06085\&d=ACS\%205-Year\% 20Estimates\%20Data\%20Profiles\&tid=ACSDP5Y2018.DP05

13. Figueroa JF, Wadhera RK, Lee D, Yeh RW, Sommers BD. Community-level factors associated with racial and ethnic disparities in COVID-19 rates in Massachusetts. Health Aff (Millwood). 2020;39:1984-92. https://doi.org/10.1377/ hlthaff.2020.01040

14. Grijalva CG, Rolfes MA, Zhu Y, McLean HQ, Hanson KE, Belongia EA, et al. Transmission of SARS-COV-2 infections in households - Tennessee and Wisconsin, AprilSeptember 2020. MMWR Morb Mortal Wkly Rep. 2020;69:1631-4. https:/ / doi.org/10.15585/mmwr.mm6944e1 
15. Grasselli G, Zangrillo A, Zanella A, Antonelli M, Cabrini L, Castelli A, et al.; COVID-19 Lombardy ICU Network. Baseline characteristics and outcomes of 1591 cases infected with SARS-CoV-2 admitted to ICUs of the Lombardy Region, Italy. JAMA. 2020;323:1574-81. https:/ / doi.org/10.1001/ jama.2020.5394

16. Garg S, Kim L, Whitaker M, O'Halloran A, Cummings C, Holstein R, et al. Hospitalization rates and characteristics of cases hospitalized with laboratory-confirmed coronavirus disease 2019 - COVID-NET, 14 states, March 1-30, 2020. MMWR Morb Mortal Wkly Rep. 2020;69:458-64. https://doi.org/10.15585/mmwr.mm6915e3

17. Bialek S, Boundy E, Bowen V, Chow N, Cohn A, Dowling N, et al.; CDC COVID-19 Response Team. Severe outcomes among cases with coronavirus disease 2019 (COVID-19) United States, February 12-March 16, 2020. MMWR Morb Mortal Wkly Rep. 2020;69:343-6. https:/ / doi.org/10.15585/ mmwr.mm6912e2

18. Qian G, Yang N, Ma AHY, Wang L, Li G, Chen X, et al. COVID-19 transmission within a family cluster by presymptomatic carriers in China. Clin Infect Dis. 2020;71:861-2.

19. Chan JF-W, Yuan S, Kok K-H, To KK, Chu H, Yang J, et al. A familial cluster of pneumonia associated with the 2019 novel coronavirus indicating person-to-person transmission: a study of a family cluster. Lancet. 2020;395:514-23. https:/ / doi.org/10.1016/S0140-6736(20)30154-9

20. Wang Z, Ma W, Zheng X, Wu G, Zhang R. Household transmission of SARS-CoV-2. J Infect. 2020;81:179-82. https:// doi.org/10.1016/j.jinf.2020.03.040

21. Haroon S, Chandan JS, Middleton J, Cheng KK. Covid-19: breaking the chain of household transmission. BMJ. 2020;370:m3181.

22. Lei $\mathrm{H}, \mathrm{Xu} X, \mathrm{Xiao} \mathrm{S}, \mathrm{Wu} \mathrm{X}, \mathrm{Shu} \mathrm{Y}$. Household transmission of COVID-19-a systematic review and meta-analysis. J Infect. 2020;81:979-97. https://doi.org/10.1016/j.jinf.2020.08.033

23. Emeruwa UN, Ona S, Shaman JL, Turitz A, Wright JD, Gyamfi-Bannerman C, et al. Associations between built environment, neighborhood socioeconomic status, and SARS-CoV-2 infections among pregnant women in New York City. JAMA. 2020;324:390-2. https://doi.org/10.1001/ jama.2020.11370

24. US Census Bureau. Percentage of overcrowded housing units, 2014-2018 American Community Survey 5-year estimates. Table B25014 [cited 2021 Jan 30]. https:/ / data.census.gov/cedsci/table?q=B25014\&tid= ACSDT5Y2018.B25014\&hidePreview=false

25. Ghinai I, Woods S, Ritger KA, McPherson TD, Black SR, Sparrow L, et al. Community transmission of SARS-CoV-2 at two family gatherings - Chicago, Illinois, February-March 2020. MMWR Morb Mortal Wkly Rep. 2020;69:446-50. https://doi.org/10.15585/mmwr.mm6915e1

26. Centers for Disease Control and Prevention. Households living in close quarters. April 18, 2020 [cited 2021 Jan 29]. https:/ / www.cdc.gov/coronavirus /2019-ncov/ daily-lifecoping/living-in-close-quarters.html

27. Test \& Trace Corps. NYC Health + Health Hospitals. Take care [cited 2021 Jan 29]. https:/ / www.nychealthandhospitals.org/test-and-trace/take-care

28. US Department of Labor, Occupational Safety and Health Administration. Safety and Health Topics. COVID-19. Hazard recognition [cited 2020 Jul 13]. https:/ / www.osha.gov/ coronavirus/hazards

29. Council of State and Territorial Epidemiologists Occupational Health Subcommittee. Recommended interim guidance for collecting employment information about COVID-19 cases [cited 2021 Jan 28]. https://cdn.ymaws.com/www.cste.org/ resource/resmgr/publications/Guidance_collecting_io_ covid.pdf

30. Pew Research Center. About half of lower-income Americans report household job or wage loss due to COVID-19. April 21, 2020 [cited 2021 Jan 28]. https:/ / www.pewsocialtrends. org/2020/04/21/about-half-of-lower-income-americansreport-household-job-or-wage-loss-due-to-covid-19

31. California Department of Public Health. COVID-19 race and ethnicity data. June 7, 2020 [cited 2021 Jan 28]. https:/ / www. cdph.ca.gov/Programs/CID/DCDC/Pages/COVID-19/ Race-Ethnicity.aspx

32. Census Reporter. 95127. ZIP code tabulation area in: Santa Clara County, CA, San Jose-Sunnyvale-Santa Clara, CA Metro Area, California, United States [cited 2021 Jan 28]. https:/ / censusreporter.org/ profiles/86000US95127-95127

33. Census Reporter. 95148. ZIP code tabulation area in: Santa Clara County, CA, San Jose-Sunnyvale-Santa Clara, CA Metro Area, California, United States [cited 2021 Jan 28]. https:/ / censusreporter.org/profiles/86000US95148-95148

34. Census Reporter. Santa Clara County. CA [cited 2021 Jan 28]. https://censusreporter.org/profiles/05000US06085-santaclara-county-ca

35. Census Reporter. Race. American Community Survey 2018 5-year estimates. Table B02001 [cited 2021 Jan 28]. https:/ / censusreporter.org/data/table/?table=B02001\&geo_ ids=86000US95148\&primary_geo_id=86000US95148\#valueT ype | estimate

36. US Census Bureau. Asian alone by selected groups. American Community Survey 2018 5-year estimates. Table B02015 [cited 2021 Jan 28]. https:/ / data.census.gov/cedsci/ table?q=B02015\&g=8600000US95148\&tid=ACSDT5Y2018. B02015\&hidePreview $=$ false

37. US Census Bureau. Hispanic or Latino origin by specific origin. American Community Survey 2018 5-year estimates. Table B03001 [cited 2021 Jan 29]. https:/ / data.census.gov/ cedsci $/$ table?q=Table $\%$ 20B03001\&tid=ACSDT5Y2018. B03001\&hidePreview $=$ false

38. Kambhampati AK, O'Halloran AC, Whitaker M, Magill SS, Chea N, Chai SJ, et al.; COVID-NET Surveillance Team. COVID-19-associated hospitalizations among health care personnel-COVID-NET, 13 states, March 1-May 31, 2020. MMWR Morb Mortal Wkly Rep. 2020;69:1576-83. https://doi.org/10.15585/mmwr.mm6943e3

39. Centers for Disease Control and Prevention. Investigating a COVID-19 case [cited 2021 Jan 29]. https:/ / www.cdc.gov/ coronavirus/2019-ncov/php/contact-tracing/contacttracing-plan/investigating-covid-19-case.html

40. Santa Clara County Public Health. County of Santa Clara Emergency Operations Center COVID-19 dashboards [cited 2021 Jan 29]. https:/ / www.sccgov.org/sites/covid19/ Pages/dashboard-demographics-of-cases-and-deaths.aspx

41. Fisher KA, Olson SM, Tenforde MW, Feldstein LR, Lindsell CJ, Shapiro NI, et al.; IVY Network Investigators; CDC COVID-19 Response Team. Telework before illness onset among symptomatic adults aged $\geq 18$ years with and without COVID-19 in 11 outpatient health care facilities - United States, July 2020. MMWR Morb Mortal Wkly Rep. 2020; 69:1648-53. https://doi.org/10.15585/mmwr.mm6944a4

Address for correspondence: Nancy Ortiz, Centers for Disease Control and Prevention, 1600 Clifton Rd NE, Mailstop V25-1, Atlanta, GA 30329-4027, USA; email: hqo5@cdc.gov 